\title{
INVESTIGATION OF REMOVAL OF HEXAVALENT CHROMIUM AND DIVALENT COBALT FROM AQUEOUS SOLUTIONS BY ORGANO-MONTMORILLONITE SUPPORTED IRON NANOPARTICLES
}

Viktoriia Prus

Department of chemical technology of ceramics and glass

National Technical University of Ukraine "Igor Sikorsky Kyiv Polytechnic Institute"

37 Peremohy ave., Kyiv, Ukraine, 03056

vika.prus.93@mail.ru

Nataliya Zhdanyuk

Department of chemical technology of ceramics and glass

National Technical University of Ukraine "Igor Sikorsky Kyiv Polytechnic Institute"

37 Peremohy ave., Kyiv, Ukraine, 03056

zhdanyukn.kpi@gmail.com

\begin{abstract}
A new class of nanoscale zero-valent iron particles supported on natural montmorillonite and organo-montmorillonite were synthesized and the feasibility for the removal of $\mathrm{Cr}(\mathrm{VI})$ and $\mathrm{Co}(\mathrm{II})$ was examined through laboratory batch test. The X-ray diffraction (XRD) and Fourier Transform Infrared spectrum (FTIR) investigation has been applied for determination of the particle size and mechanism of remediation process. The aim of this study was to enhance the reduction of persistent environmental pollutants difficult to degrade by immobilization of nanoscale zero-valent iron on an organo-montmorillonite. Batch experiments indicated that the reduction of both $\mathrm{Cr}(\mathrm{VI})$ and $\mathrm{Co}(\mathrm{II})$ was much greater with organo-montmorillonite supported iron nanoparticles reaching removal rate up to $98.5 \%$ and $95.6 \%$ respectively at the initial metal concentrations of $50 \mathrm{mg} / \mathrm{L}$. Iron and crystalline iron oxide were detected by X-ray diffraction patterns. In the FTIR spectrum, $\mathrm{CH}_{2}$ groups were found in iron nanoparticles supported on hexadecyltrimethylammonium bromide modified montmorillonite (HDTMA-Mont/nZVI) particles but were significantly weakened in comparison with the spectrum of hexadecyl trimethylammonium bromide (HDTMA). Other factor that affects the efficiency of heavy metals removal such as $\mathrm{pH}$ values was also investigated. The obtained data and review of the current literature have given the opportunity to figure out the mechanisms of $\mathrm{Cr}(\mathrm{VI})$ and $\mathrm{Co}(\mathrm{II})$ removal which may thus promote the industrial application of nZVI technique in environmental remediation by changing the hydrophilic - hydrophobic properties of source systems.

Keywords: organo-montmorillonite, zero-valent iron nanoparticles, contaminants, aquatic environment, absorption, remediation chromium, cobalt, reduction, XRD, FTIR.

\section{Introduction}

Iron nanoparticles are very effective for the removal of a wide range of contaminants, such as chlorinated organics, heavy metals and radionuclides, providing enormous flexibility for both in situ and ex situ applications. Nevertheless, a major obstacle for more effective remediation still remains, which involves tendency of reactive nanoparticles agglomerate with rapid sedimentation, causing limited mobility of the nanoparticles in an aquatic environment [1-5].

The usage of this composite as a supporting material is justified by the fact that clay minerals are abundant, environmental-friendly and much cheaper than activated carbon and technologies such as pump-and-treat, steam treatment, flushing with solvents and surfactants and attenuation via bio-and phytoremediation [1,6-8]. Moreover, montmorillonite is a kind of clay mineral with a layered structure, high surface area and strong adsorption characteristic.

Comparisons were made between both unsupported and supported iron nanoparticles in removal of different metallic ions. In this study, $\mathrm{Cr}(\mathrm{VI})$ and $\mathrm{Co}(\mathrm{II})$ were chosen as typical pollutants to assess the performance of iron nanoparticles supported by organo-montmorillonite. Research of contaminant removal demonstrated that the remediation mechanism varies depending on the contaminant of interest. A combination of surfactants and montmorillonite probably enhances the transport of iron nanoparticles through the contamination plume in the subsurface environment.
\end{abstract}




\section{Experimental part and discussion}

\section{1. Materials and Methods}

Montmorillonite was obtained from Cherkasy, Ukraine, potassium dichromate $\left(\mathrm{K}_{2} \mathrm{Cr}_{2} \mathrm{O}_{7}\right)$, ferrous chloride tetrahydrate $\left(\mathrm{FeSO}_{4} \cdot 7 \mathrm{H}_{2} \mathrm{O}\right)$, and hexadecyltrimethylammonium bromide (HDTMA) $\left.\left(\mathrm{C}_{16} \mathrm{H}_{33}\right) \mathrm{N}\left(\mathrm{CH}_{3}\right)_{3} \mathrm{Br}\right)$ ), sodium borohydrate $\mathrm{NaBH}_{4}$ was purchase from (Merck, Germany). All presented chemicals were obtained in high purity and used as received. Montmorillonite had a cation exchange capacity (CEC) of $1 \mathrm{meq} / \mathrm{g}$. [9].

The organo-montmorillonite was prepared due to dispersing $10 \mathrm{~g}$ of montmorillonite in $200 \mathrm{ml}$ deionized water with ultrasound for $15 \mathrm{~min}$. A solution of HDTMA $3.6445 \mathrm{~g}$ in $20 \mathrm{~mL}$ water was added under magnetic stirring IKA RCT basic safety control (IKAMAG, IKA, Germany). After 3 hours of reaction with stirring at $60^{\circ} \mathrm{C}$ the final suspension was subjected to centrifugation followed by continual washing after which it was dried at $80{ }^{\circ} \mathrm{C}$ for 10 hours, and finally pulverized to pass through a $200-\mu \mathrm{m}$ mesh sieve. The similar preparation method was reported previously [10, 11].

To investigate the infrared spectra used $\mathrm{KBr}$ pellet method $-3 \mathrm{mg}$ of the sample is well mixed into $300 \mathrm{mg}$ fine alkali halide (KBr) was performed on Fourier spectrometer Spectrum-One FT-IR (Perkin-Elmer, USA) in the range $4000-4500 \mathrm{~cm}^{-1}$ where the sample was being subjected twenty consecutive times to scan with the resolution of $4 \mathrm{~cm}^{-1}$.

The FTIR analysis was performed in an ultrasonic disperser UZDN - 2T.

$\mathrm{X}$-ray analysis of initial and modified samples was conducted with the help of a diffractometer DRON - 4-07 (NPP «Burevestnik», Russia Federation) in the range $1-60^{\circ}(2 \theta)$ with the usage of $\mathrm{CuK} \alpha$-radiation.

Removal processes of $\mathrm{Cr}(\mathrm{VI})$ from water were studied on standard test solutions, which were being prepared with distilled water and use of $\mathrm{K}_{2} \mathrm{Cr}_{2} \mathrm{O}_{7}$ and $1 \mathrm{M} \mathrm{NaCl}$ solution in order to obtain a desired ionic strength ( $\mathrm{I}=0,01)$. Ionometer I - I60M (Sistema Optimum, ChP, Ukraine) was used for standard test solutions' $\mathrm{pH}$ value adjustment with the use of $\mathrm{NaOH}$ and $\mathrm{HCl}$ solutions.

Experiments on $\mathrm{Cr}(\mathrm{VI})$ removal were carried out in static conditions at $25{ }^{\circ} \mathrm{C}$ temperature. Mineral sample in the experiments was $0.1 \mathrm{~g}$, liquid phase volume $-50 \mathrm{~cm}^{3}$. After reaching adsorption equilibrium ( within 1 hour) liquid phase was separated by centrifugation in which subsequently the equilibrium concentration of $\mathrm{Cr}(\mathrm{VI})$ was determined by spectrophotometry method Spectrophotometer UNICO 2100 UV (UNICO, USA), going by the standard methodology with the use of diphenylcarbazide reagent at wavelength of $540 \mathrm{~nm}$.

\section{2. Synthesis of zero-valent iron particles}

Zero-valent iron particles (nZVI) were prepared by a liquid phase reduction method with borohydrate. This method is considered as the most common one due to its productivity and simplicity. The major part is to prepare the solution of FeSO and $\mathrm{NaBH}_{4}$. In each batch, $12.4330 \mathrm{~g}$ of $\left(\mathrm{FeSO}_{4} \cdot 7 \mathrm{H}_{2} \mathrm{O}\right)$ was dissolved in $100 \mathrm{ml}$ solution consisted of $80 \mathrm{ml} \mathrm{H} 2 \mathrm{O}$ and $20 \mathrm{ml}$ absolute ethanol. It has been reported that the use of ethanol prevents oxidation of the particles during the preparation greatly [12]. Then amounts of $2 \mathrm{~g}$ montmorillonite (Mont) or : organo-montmorillonite (HDTMA-Mont) were dispersed in the $\mathrm{FeSO}_{4}$ solution by magnetic stirring. $4.1635 \mathrm{~g}$ of $\mathrm{NaBH}_{4}$ was dissolved in $110 \mathrm{ml}$ of deionized water in order to obtain $1 \mathrm{M}$ solution for preparation of $\mathrm{NaBH}_{4}$ solution. Finally the $\mathrm{NaBH}_{4}$ solution was added into montmorillonite $-\mathrm{FeSO}_{4}$ dispersion. Synthetic sorbents title respectively Mont/nZVI and HDTMA-Mont/nZVI.

\section{3. X-ray diffraction (XRD) and Fourier Transform Infrared (FTIR) spectra analysis}

Two reflections are shown at $1^{\circ}$ and $5^{\circ}$ on XRD, the second of which associated with the (001) reflection of montmorillonite, the same as with Mont/iron and the first one is attributed to the large $\mathrm{d}$-spacing, interpretation of which is unclear. It has been assumed that it is reflection of the existence of a highly correlated porous structure. Based on recent research in the structure of supported iron nanoparticles, the schematic representation of the sectional structure of the clay minerals supported iron nanoparticles was suggested [2]. The clay interlayer spaces accommodated the iron nanoparticles thus preventing them from aggregation. It was also suggested that the three-dimen- 
sional co-aggregation of clay platelets and iron hydroxyl cations or iron oxide nanoparticles caused the large d-spacing at $1^{\circ}$ angle.

The indication of the zero-valent iron having been successfully supported on organo-montmorillonite is an obvious characteristic diffraction peak of $\mathrm{Fe}^{0}$ appearing at $2 \theta=45^{\circ}$ for both nZVI and Mont/iron on FTIR spectra [1-3].The $\mathrm{CH}_{2}$ groups bands of the alkyl chains were weakened in the spectrum of HDTMA-Mont/nZVI. Presumably these shifts in the $\mathrm{CH}_{2}$ vibrational bands are due to the strong interactions between surfactant tails and the mineral surface [13]. Accordingly, there may be structural changes in that adsorbed surfactant molecules change from the aggregated-cluster state (e. g., micelle-like state) to a more dispersed state lying on the surface, preferring an interaction with the mineral surface instead with alkyl groups at low surface coverage.

\section{4. Removal performance of $\mathrm{Cr}$ (VI) and $\mathrm{Co}$ (II) analysis}

According to the various references, the core-shell structure of the nanoparticles is responsible for great ability of nZVI to absorb metal ions from aqueous solution by multiple mechanisms, which are closely related to reduction and precipitation, electrostatic adsorption, complex formation. It has been reported that oxidation-reduction mechanism seems to be quite effective in the uptake of number of ions which have higher standard reduction potential than $\mathrm{Fe}^{2+}$. These include $\mathrm{Ag}^{+}, \mathrm{Cu}^{2+}, \mathrm{Ni}^{2+}, \mathrm{Pb}^{2+}, \mathrm{Cr}(\mathrm{VI}), \mathrm{As}(\mathrm{III})$ and $\mathrm{As}(\mathrm{V})$ [14-17].

Since $\mathrm{Co}^{2+}$ is higher in the electrochemical series than $\mathrm{Fe}^{2+}$ it is worth to assume that the adsorption of $\mathrm{Co}^{2+}$ takes place due to a redox reaction resulting information of insoluble $\mathrm{Co}^{0}$. However, in the other study it has not been confirmed that removed cobalt was present in its zero-valent form. On the basis of XPS analysis author suggests that $\mathrm{Co}^{2+}$ ions were fixed by the oxo hydroxyl groups at the surface of the shell of iron nanoparticles or simply precipitated on that surface in the form of $\mathrm{Co}(\mathrm{OH})_{2}$. The fact that $\mathrm{Co}^{2+}$ ions were not exposed to reduction has also been shown by the XRD analysis, according to which there was no signal that matches with the basic reflection of metallic Co.

The mechanisms of $\mathrm{Cr}(\mathrm{VI})$ reduction by $\mathrm{Fe}^{0}$ are a cyclic and involve multiple reactions of electrochemical corrosion. The removal of $\mathrm{Cr}^{6+}$ can be achieved by a redox reaction in which ferric ion (Fe(III) and chromium ion $\mathrm{Cr}$ (III) are produced. Chromium (III), in turn, may be removed through precipitation or co-precipitation on account of mixed $\mathrm{Fe}$ (III) and $\mathrm{Cr}$ (III) hydroxide as shown in following equations [5]:

$$
\begin{gathered}
\mathrm{Cr}^{6+}+\mathrm{Fe}^{0} \rightarrow \mathrm{Cr}^{3+}+\mathrm{Fe}^{3+} \\
(1-\mathrm{x}) \mathrm{Fe}^{3+}+(\mathrm{x}) \mathrm{Cr}^{3+}+3 \mathrm{H}_{2} \mathrm{O} \rightarrow\left(\mathrm{Cr}_{\mathrm{x}} \mathrm{Fe}_{(1-\mathrm{x})}\right)(\mathrm{OH})_{3(\mathrm{~s})}+3 \mathrm{H}^{+} \\
(1-\mathrm{x}) \mathrm{Fe}^{3+}+(\mathrm{x}) \mathrm{Cr}^{3+}+2 \mathrm{H}_{2} \mathrm{O} \rightarrow \mathrm{Fe}_{(1-\mathrm{x})} \mathrm{Cr}_{\mathrm{x}} \mathrm{OOH}_{(\mathrm{s})}+3 \mathrm{H}^{+}
\end{gathered}
$$

Besides, $\mathrm{Cr}(\mathrm{VI})$ can be reduced by $\mathrm{Fe}(\mathrm{II})$ or atomic/molecular hydrogen $\left(\mathrm{H} / \mathrm{H}_{2}\right)$, which is derived from the oxidation of zero-valent iron. Since the outer oxide film on the nZVI particles limits the interaction between iron core and $\mathrm{Cr}(\mathrm{VI})$ species, there is possibility of reduction by electrons originating directly from $\mathrm{Fe}^{0}$ core, if its oxide layer shell is conductive. It can also be suggested that the iron nanoparticles work as generators of reducing species ( $\mathrm{Fe}(\mathrm{II}),\left(\mathrm{H} / \mathrm{H}_{2}\right)$ and removing agents ( $\mathrm{Fe}$ hydroxides and oxide) rather than as direct reducing agents, based on the fact that the $\mathrm{Fe}$ (II) cations diffuse more favorably through the porous oxide film of nZVI toward the contaminant species [18]. Although it is been reported that the HDTMA-Mont/nZVI particles and unsupported iron nanoparticles reacted with metallic ions in the same mechanism [2], the future research is required on surface modification techniques and complimentary materials analysis to elucidate the mechanisms via which contaminants can be successfully removed from solution by nanocomposite.

The absorption of $\mathrm{Cr}(\mathrm{VI})$ decreased with increasing the initial $\mathrm{pH}$. The reason for this is that the $\mathrm{HCrO}_{4}$ - form of $\mathrm{Cr}(\mathrm{VI})$ is dominant in lower $\mathrm{pH}$ whilst the surface of the adsorbent has 
a positive charge. By increasing of $\mathrm{pH}$, the $\mathrm{HCrO}_{4}$ - species is supplanted by other forms namely $\mathrm{CrO}_{4}^{2-}$ and $\mathrm{Cr}_{2} \mathrm{O}_{7}^{2-}$. Basically, the drop in the adsorption of $\mathrm{Cr}(\mathrm{VI})$ is due to the competition between the anions $\mathrm{CrO}_{4}^{2-}$ and $\mathrm{OH}^{-}[2,3]$.

As the $\mathrm{pH}$ increases, insoluble hydroxides of these metals could arise, the thing that enhances their removal. On the contrary, the lower removal percentages at low $\mathrm{pH}$ values, in the case of $\mathrm{Co}(\mathrm{II})$ adsorption, can be explained by the strong electrostatic repulsions between the Mont/nZVI particles and the cationic metal ions. At low $\mathrm{pH}$ media, Mont/nZVI has high positive surface potentials and hence high positive surface charges, the thing that causes repulsions with the cationic species of $\mathrm{Co}^{2+}$ in the solution [11].

\section{Results of investigation}

\section{1. X-ray diffraction (XRD)}

The basal spacing of Mont was $1.24 \mathrm{~nm}$, which is common for Na-montmorillonite [19-21]. The basal spacing enlarged up to after the reaction with hexadecyltrimethylammonioum ions [1-3]. The XRD diffractogram of the synthesized nZVI particle has characteristic $2 \theta$ value of $45^{\circ}$, and signal for iron oxides with a $2 \theta$ value of $32^{\circ}$ and $35^{\circ}$ were found (Fig. 1). These diffraction patterns along with the calculation of the Scherrer equation proved that the iron is mainly in its zero-valent state.
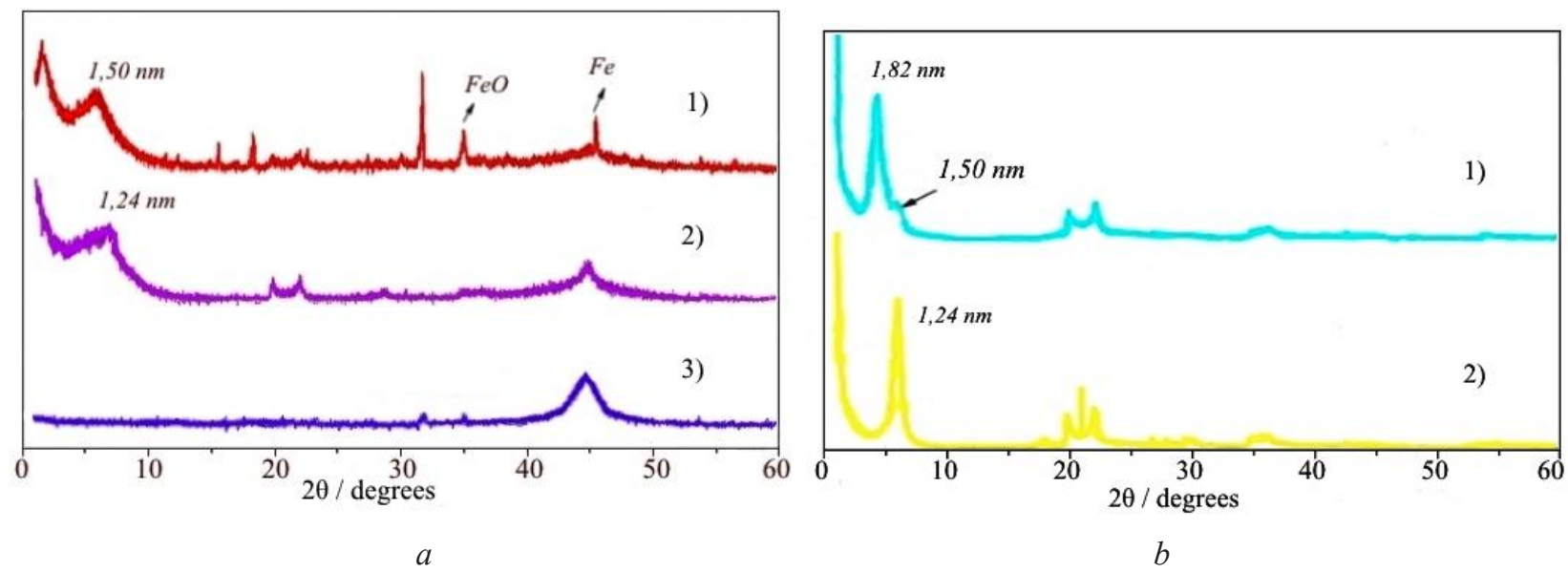

Fig. 1. X-ray diffraction patterns of: $a$ - supported iron nanoparticles (HDTMA-Mont/nZVI (1), Mont/nZVI (2)) and iron nanoparticles (3); $b$ - supporting materials: HDTMA-Mont (1) and Mont (2)

The particle size was determined due to the Scherrer formula for X-ray particle size calculation:

$$
\mathrm{D}=\frac{\mathrm{k} \lambda}{\beta \cos \theta}
$$

Since the X-ray wavelength $(\lambda)$ is equal to $1.5418 \AA$.

Bragg's angle is $45^{\circ}$ and $\beta$ (line broadening at half the maximum intensity) is 0.2 it has been found out that the approx size of nanoparticles equals $26,59 \mathrm{~nm}$ which falls into the nanodomain $(<80 \mathrm{~nm})$ and corresponds with the data has been previously reported [22].

\section{2. Fourier Transform Infrared (FTIR) spectra}

For HDTMA-Mont, bands at 2920 and $2850 \mathrm{~cm}^{-1}$ were due to groups of the alkyl chains.

In the IR spectrum of the iron-montmorillonite (OMMT/NNZ) observed weakening bands $\left(-\mathrm{CH}_{2}-\right.$ groups alkyl chains at 2920 and $\left.2850 \mathrm{~cm}^{-1}\right)$. New band is also appeared in the spectra of these samples at $625 \mathrm{~cm}^{-1}$, which is characteristic for stretching fluctuations Fe-O (Fig. 2). 


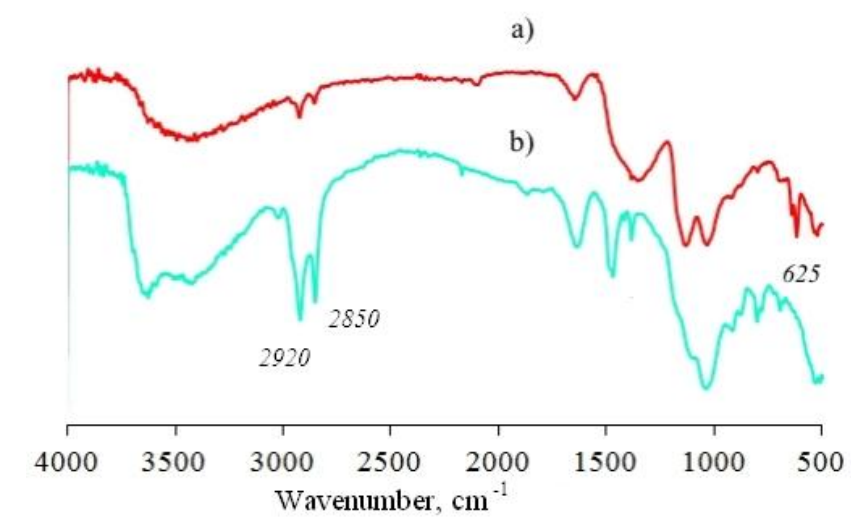

Fig. 2. FTIR spectra: a - supported iron nanoparticles (HDTMA-Mont/nZVI); $\mathrm{b}$ - organic montmorillonite (HDTMA-Mont)

\section{3. Reduction performance with $\mathrm{Cr}(\mathrm{VI})$ and $\mathrm{Co}(\mathrm{II})$ solution}

As shown on figures, the reduction of $\mathrm{Co}^{2+}$ decreased as HDTM-Mont/nZVI > Mont/nZVI $>$ nZVI $>$ Mont $>$ Powdered iron $>$ HDTM-Mont whereas for $\mathrm{Cr}^{6+}$ reduction the following tendency can be observed: HDTMA-Mont/nZVI $>$ Mont/nZVI $>$ nZVI $>$ HDTM-Mont $>$ Powdered iron $>$ Mont (Fig. 3).

Montmorillonite has a net negative structural charge due to isomorphic substitution of cations in the crystal lattice [21]. On account of this negative charge, Mont has little or no affinity for anionic species. However, modifying clay mineral surfaces with surfactants converts the hydrophilic silicate surface to the positively charged hydrophobic one. Thereby, HDTM-Mont reveals more reactivity towards the $\mathrm{Cr}^{6+}$ removal compared to unmodified Mont, reaching adsorption values of $99.8 \%$ at initial $\mathrm{Cr}^{6+}$ concentration equals $10 \mathrm{mg} / \mathrm{L}$ (Table 1). In the case of the $\mathrm{Co}^{2+}$ removal the reverse pattern has been exhibited: the better adsorption level has been achieved using unmodified montmorillonite due to positive charged aqueous $\mathrm{Co}^{2+}$ ions.

The absorption of $\mathrm{Cr}(\mathrm{VI})$ decreased with increasing the initial $\mathrm{pH}$. The reason for this is that the $\mathrm{HCrO}_{4}$ - form of $\mathrm{Cr}(\mathrm{VI})$ is dominant in lower $\mathrm{pH}$ whilst the surface of the adsorbent has a positive charge. By increasing of $\mathrm{pH}$, the $\mathrm{HCrO}_{4}$ - species is supplanted by other forms namely $\mathrm{CrO}_{4}^{2-}$ and $\mathrm{Cr}_{2} \mathrm{O}_{7}^{2-}$. Basically, the drop in the adsorption of $\mathrm{Cr}(\mathrm{VI})$ is due to the competition between the anions $\mathrm{CrO}_{4}^{2--}$ and $\mathrm{OH}^{-}[2,3]$.

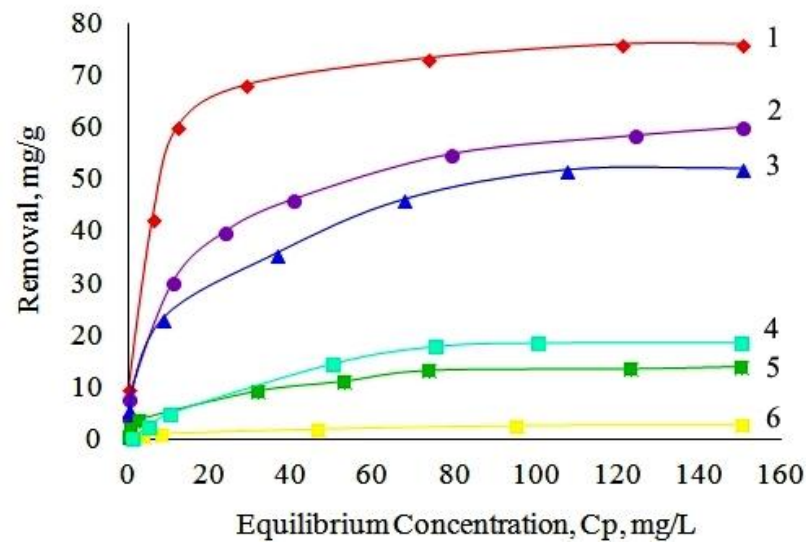

$a$

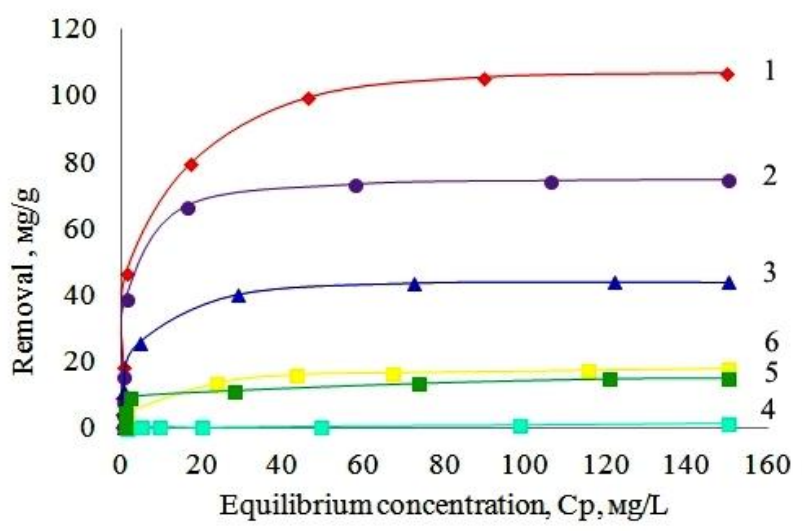

$b$

Fig. 3. Removal rate of: $a-\mathrm{Cr}(\mathrm{VI})$ and $b-\mathrm{Co}(\mathrm{II})$ as a function of equilibrium concentration (1 - HDTMA-Mont/nZVI, 2 - Mont/nZVI, 3 - nZVI, 4 - iron powder, 5 - HDTMA-Mont, 6 - Mont) 
Table 1

The equilibrium values corresponding to the uptake of $\mathrm{Cr}^{6+}$ and $\mathrm{Co}^{2+}$ ions by 1:1 HDTMA-Mont: nZVI and samples for various initial metal concentrations

\begin{tabular}{|c|c|c|c|c|c|c|}
\hline \multirow{2}{*}{$\begin{array}{l}\text { HDTMA-Mont:nZVI } \\
\qquad[\mathrm{Co}]_{0}[\mathrm{Cr}]_{0}, \mathrm{mg} / \mathrm{L}\end{array}$} & \multicolumn{3}{|c|}{$1: 1$} & \multicolumn{3}{|c|}{$1: 1$} \\
\hline & {$[\mathrm{Cr}]_{1}$} & {$[\mathbf{C r}]_{\mathrm{s}}$} & \% Removal & {$[\mathrm{Co}]_{1}$} & {$[\mathrm{Co}]_{\mathrm{s}}$} & \% Removal \\
\hline 200 & 89.6 & 55.2 & 55.2 & 120.7 & 75.9 & 39.6 \\
\hline 150 & 46 & 52.0 & 69.3 & 78.7 & 68.3 & 47.5 \\
\hline 100 & 20.3 & 39.9 & 79.7 & 52.5 & 45.5 & 47.5 \\
\hline 75 & 1.0 & 24.5 & 97.9 & 7.3 & 64.8 & 90.2 \\
\hline 50 & 0.3 & 9.8 & 98.5 & 2.2 & 45.8 & 95.6 \\
\hline 10 & 0.1 & 5.0 & 99.8 & 0.1 & 9.6 & 99.9 \\
\hline 5 & 0.1 & 2.4 & 97.3 & 0.1 & 4.7 & 98.8 \\
\hline 1 & 0.0 & 0.5 & 92.6 & 0.0 & 0.9 & 96.9 \\
\hline
\end{tabular}

\section{4. Effect of $\mathrm{pH}$ on metals removal}

The effect of $\mathrm{pH}$ was determined by examining removal of $\mathrm{Cr}(\mathrm{VI})$ and $\mathrm{Co}(\mathrm{II})$ at the following constant factors: Temperature $=25^{\circ} \mathrm{C}$, agitation speed $=250 \mathrm{rpm}, \mathrm{Cr}$ concentration $=50 \mathrm{mg} \mathrm{L}^{-1}$, nanocomposite dosage $-0.1 \mathrm{~g} \mathrm{~L}^{-1}$, contact time $=60$ minutes. In connection with the high resolution obtained sorbent to extract ions $\mathrm{Cr}$ (VI) from aqueous solutions was decided to put the experiment in terms of chromium ions concentration of $50 \mathrm{mg} / \mathrm{L}$. Due to the high ability to removal of ions of $\mathrm{Cr}$ (VI) from aqueous solutions, it was decided to put the experiment at the these conditions.

As the $\mathrm{pH}$ increases, insoluble hydroxides of these metals could arise, the thing that enhances their removal $(\mathbf{F i g} . \mathbf{4}, \boldsymbol{a})$. On the contrary, the lower removal percentages at low $\mathrm{pH}$ values, in the case of $\mathrm{Co}(\mathrm{II})$ adsorption (Fig. $\mathbf{4}, \boldsymbol{b}$ ), can be explained by the strong electrostatic repulsions between the Mont/nZVI and the cationic metal ions.

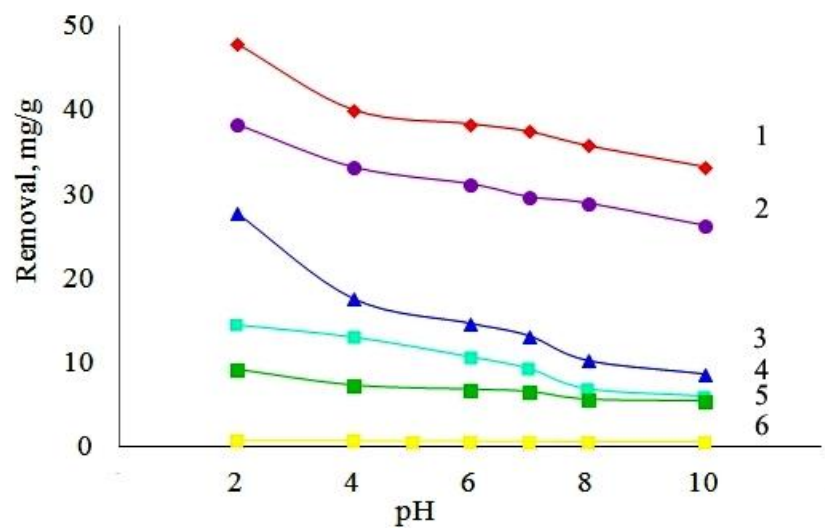

$a$

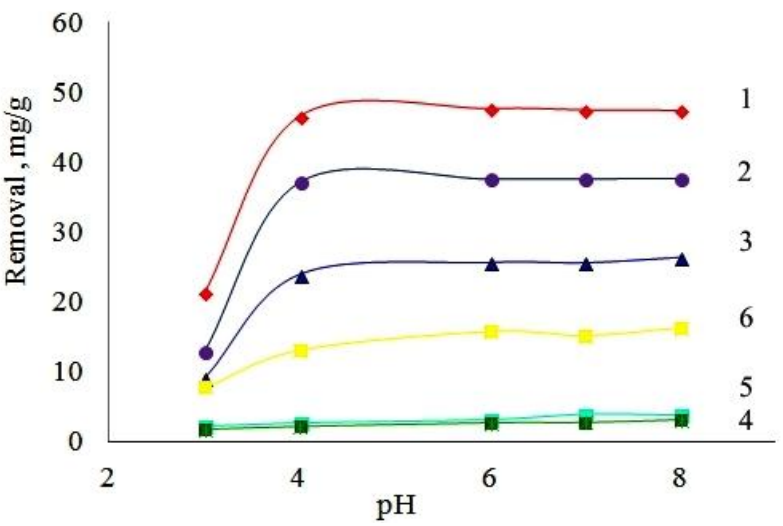

$b$

Fig. 4. Removal rate of: $a-\mathrm{Cr}(\mathrm{VI})$ and $b-\mathrm{Co}(\mathrm{II})$ as a function of $\mathrm{pH}$ (1 - HDTMA-Mont/nZVI, 2 - Mont/nZVI, 3 -nZVI, 4 - iron powder, 5 - HDTMA-Mont, 6 - Mont)

At low $\mathrm{pH}$ media, Mont/nZVI have high positive surface potentials and hence high positive surface charges, the thing that causes repulsions with the cationic species of $\mathrm{Co}^{2+}$ in the solution [14].

\section{Conclusions}

Nanocomposite supported iron nanoparticles appeared to be more effective in terms of the removal of $\mathrm{Cr}(\mathrm{VI})$ and $\mathrm{Co}(\mathrm{II})$ than unsupported iron nanoparticles. 
From the current study it is clear that the mechanism of removal is not the same for each contaminant. The $\mathrm{pH}$ of the aqueous solution is vital to the adsorption of both $\mathrm{Cr}$ (VI) and $\mathrm{Co}$ (II) possibly because of the presence of various species and the surface charge of adsorbent. Finally, the use of organo-montmorillonite could greatly enhance the reduction activity of nanoscale zerovalent iron due to its capability to prevent their aggregation.

The sorption rate of chromium was found to be increased with decrease in initial $\mathrm{pH}$ of solution and gone up with equilibrium concentration. On the contrary, however, the cobalt removal efficiency dropped with growth in initial $\mathrm{pH}$.

Nanocomposite showed an outstanding ability to remove metal ions because of high surface activity and low particle size. After the contact with $\mathrm{Cr}(\mathrm{VI})$ and $\mathrm{Co}(\mathrm{II})$, the reduction of those was highest with HDTMA-Mont/nZVI, followed by Mont/nZVI and unsupported nanoparticles, what may thus offer an economically and environmentally friendly usage of organoclay nanocomposite as an exceptional solution to one of the most aggravating ecological problems.

For instance, a major challenge for groundwater remediation of reactive nanomaterials is their strong tendency to agglomerate, with rapid sedimentation and consequently limited mobility of the nanoparticles in aqueous environment. The present findings highlight the possibility of investigated nanocomposites being used as a suitable material for in situ remediation of heavy metal contaminated groundwater. Also the effect of such important factors as hydrophilic - hydrophobic properties of source systems and $\mathrm{pH}$ on remediation process was demonstrated, which in turn may define optimal synthesis parameters of porous nanocomposites and ways of regulation their properties.

The obtained data and reaction mechanism analysis may also give rise to a further thorough investigation of inorganic contaminants removal from solutions with more complex chemical composition, namely containing multiple inorganic contaminants at the same time, which is essential for purification of aquatic environment under abiotic conditions.

\section{References}

[1] Li, S., Wu, P., Li, H., Zhu, N., Li, P., Wu, J., Dang, Z. (2010). Synthesis and characterization of organo-montmorillonite supported iron nanoparticles. Applied Clay Science, 50 (3), 330-336. doi: 10.1016/ j.clay.2010.08.021

[2] Wu, P., Li, S., Ju, L., Zhu, N., Wu, J., Li, P., Dang, Z. (2012). Mechanism of the reduction of hexavalent chromium by organo-montmorillonite supported iron nanoparticles. Journal of Hazardous Materials, 219-220, 283-288. doi: 10.1016/j.jhazmat.2012.04.008

[3] Pang, Z., Yan, M., Jia, X., Wang, Z., Chen, J. (2014). Debromination of decabromodiphenyl ether by organo-montmorillonite-supported nanoscale zero-valent iron: Preparation, characterization and influence factors. Journal of Environmental Sciences, 26 (2), 483-491. doi:10.1016/s1001-0742(13)60419-2

[4] Scott, T. B., Popescu, I. C., Crane, R. A., Noubactep, C. (2011). Nano-scale metallic iron for the treatment of solutions containing multiple inorganic contaminants. Journal of Hazardous Materials, 186 (1), 280-287. doi: 10.1016/j.jhazmat.2010.10.113

[5] Ponmani, S., Udayasoorian, C. (2013). Zero Valent Iron (ZVI) nanocomposite for the removal of hexavalent chromium from aqueous solution. International Journal of Scientific and Engineering Research, 11, 588-593.

[6] Harwell, J. H., Sabatini, D. A., Knox, R. C. (1999). Surfactants for ground water remediation. Colloids and Surfaces A: Physicochemical and Engineering Aspects, 151 (1-2), 255-268. doi: 10.1016/s09277757(98)00785-7

[7] Merino, J., Bucalá, V. (2007). Effect of temperature on the release of hexadecane from soil by thermal treatment. Journal of Hazardous Materials, 143 (1-2), 455-461. doi: 10.1016/j.jhazmat.2006.09.050

[8] Slater, G. F., Sherwood Lollar, B., Sleep, B. E., Edwards, E. A. (2001). Variability in Carbon Isotopic Fractionation during Biodegradation of Chlorinated Ethenes: Implications for Field Applications. Environmental Science \& Technology, 35 (5), 901-907. doi: 10.1021/es001583f

[9] Tarasevich, Y. I. (1981). Pryrodnye sorbenty v protsessah ochistki vody Kyiv: Naukova Dumka, 208.

[10] Handbook of Clay Science (2006). Developments in Clay Science. doi: 10.1016/s1572-4352(05) x0100-3 
[11] Golembiovskyj, A. O. (2014). Physical and chemical organoclay synthesis features for adsorption of chromium. Eastern-European Journal of Enterprise Technologies, 1(6 (67)), 4-7. doi: 10.15587/17294061.2014.20660

[12] Qian, H., Wu, Y., Liu, Y., Xu, X. (2008). Kinetics of hexavalent chromium reduction by iron metal. Frontiers of Environmental Science and Engineering in China, 2 (1), 51-56. doi:10.1007/s11783-008-0010-3

[13] Lee, S., Kim, S. (2002). Adsorption of naphthalene by HDTMA modified kaolinite and halloysite. Applied Clay Science, 22 (1-2), 55-63. doi: 10.1016/s0169-1317(02)00113-8

[14] Çağrı, Ü. (2007). A Thesis Submitted to the Graduate School of Engineering and Science of İzmir Institute of Technology.

[15] Ponder, S. M., Darab, J. G., Mallouk, T. E. (2000). Remediation of Cr(VI) and Pb(II) Aqueous Solutions Using Supported, Nanoscale Zero-valent Iron. Environmental Science and Technology, 34 (12), 2564-2569. doi: 10.1021/es9911420

[16] Kanel, S. R., Grenèche, J.-M., Choi, H. (2006). Arsenic(V) Removal from Groundwater Using Nano Scale Zero-Valent Iron as a Colloidal Reactive Barrier Material. Environmental Science \& Technology, 40 (6), 2045-2050. doi: 10.1021/es0520924

[17] Li, X., Zhang, W. (2007). Sequestration of Metal Cations with Zerovalent Iron NanoparticlesA Study with High Resolution X-ray Photoelectron Spectroscopy (HR-XPS). The Journal of Physical Chemistry C, 111 (19), 6939-6946. doi: 10.1021/jp0702189

[18] Petala, E., Dimos, K., Douvalis, A., Bakas, T., Tucek, J., Zbořil, R., Karakassides, M. A. (2013). Nanoscale zero-valent iron supported on mesoporous silica: Characterization and reactivity for $\mathrm{Cr}(\mathrm{VI})$ removal from aqueous solution. Journal of Hazardous Materials, 261, 295-306. doi: 10.1016/j.jhazmat.2013.07.046

[19] Rutherford, D. W. (1997). Effects of Exchanged Cation on the Microporosity of Montmorillonite. Clays and Clay Minerals, 45 (4), 534-543. doi: 10.1346/ccmn.1997.0450405

[20] Tao, L., Xiao-Feng, T., Yu, Z., Tao, G. (2010). Swelling of K + , Na + and Ca 2+-montmorillonites and hydration of interlayer cations: a molecular dynamics simulation. Chinese Physics B, 19 (10), 109101. doi: 10.1088/1674-1056/19/10/109101

[21] Yusof, A. M., Malek, N. A. N. N. (2009). Removal of Cr(VI) and As(V) from aqueous solutions by HDTMA-modified zeolite Y. Journal of Hazardous Materials, 162 (2-3), 1019-1024. doi: 10.1016/ j.jhazmat.2008.05.134

[22] Jamei, M., Khorsavi, M., Anvaripour B. (2013). Degradaton of oil from soulising nano zero valent iron. Science International, 25 (4), 863-867. 